\title{
MONITORING WITH A MODIFIED ROBEL POLE ON MEADOWS IN THE CENTRAL BLACK HILLS OF SOUTH DAKOTA
}

\author{
Daniel W. Uresk ${ }^{1}$ and Ted A. Benzon ${ }^{2}$
}

\begin{abstract}
Aвstract.-This study using a modified Robel pole was conducted in the central Black Hills, South Dakota. The objectives were to test the relationship between visual obstruction readings and standing herbage, develop guidelines for monitoring, and estimate sample size. The relationship between visual obstruction and standing herbage was linear with 2 segments in a piecewise model. Regression coefficients were highly significant $(P \leq 0.001)$. Standard error of the estimate for a single mean was $373 \mathrm{~kg} \cdot \mathrm{ha}^{-1}$. Herbage ranged from 89 to $3821 \mathrm{~kg} \cdot \mathrm{ha}^{-1}$ with a mean of $1416 \mathrm{~kg} \cdot \mathrm{ha}{ }^{-1}$. The average number of visually obstructed bands was 6.4 and ranged from 0.21 to 20.4. Cluster analyses grouped the visual obstruction readings into 3 management categories: short, medium, and tall. A minimum of 3 transects (20 stations per transect) is recommended for monitoring areas $\leq 259$ ha ( 1 section) to be within $20 \%$ of the mean at $80 \%$ confidence. The protocol developed to monitor standing herbage is accurate, precise, and easy to apply. This tool provides pertinent information for managers to develop guidelines based on the bands and/or standing herbage for monitoring livestock and wildlife use.
\end{abstract}

Key words: Robel pole, vegetation, obstruction, height-density, structure, prediction, livestock, wildlife.

Direct harvesting of vegetation is considered the most reliable method of monitoring standing herbage. However, this method is very expensive and too time consuming to be practical for monitoring purposes. Other methods and techniques have been developed including double sampling (Pechanec and Pickford 1937), which involves visually estimating plant species or categories in a number of quadrats and then clipping, usually 1 quadrat of every 10 estimated, to determine a correction factor. However, this method is also time consuming and expensive, but less so than clipping alone. Managers need an efficient method to measure standing herbage to make immediate management decisions. The Robel pole has received much attention as a simple, fast, and economical tool to monitor standing herbage and vegetative structure. Once the relationship between visual obstruction readings (VOR) and standing herbage has been established, the pole requires only small inputs of labor and expense for monitoring rangelands and mountain meadows (Thomas et al. 1964, Pase and Thilenius 1968, Robel et al. 1970, Volesky et al. 1999, Benkobi et al. 2000, Uresk et al. 2000, Vermeire and Gillen 2001, Vermeire et al. 2002).
Ponderosa pine (Pinus ponderosa) dominates the native vegetation on most Black Hills forests with interspersed meadows (Pase and Thilenius 1968, Severson and Boldt 1977, Hoffman and Alexander 1987). However, management of public lands is changing. A practical monitoring technique that relates vegetation production on meadowlands to meet the needs of livestock and wildlife is limited on the Black Hills.

The objectives of this study were to (1) determine the relationship between modified visual obstruction readings of vegetation and standing herbage, (2) develop guidelines based on $1.27-\mathrm{cm}$ (0.5-inch) bands for monitoring vegetation based on structure and standing herbage, and (3) estimate sample size of transects needed for monitoring with estimates of precision and accuracy.

\section{STUdy AREA}

The study area was in the central Black Hills, South Dakota. This area is characterized by stands of ponderosa pine interspersed with meadows, parks, and other openings that make up approximately one-fourth of the land area. Average annual precipitation varies from 41 $\mathrm{cm}$ in the foothills to $56 \mathrm{~cm}$ at higher elevations (Orr 1959), and most precipitation falls

${ }^{1}$ USDA Forest Service, Rocky Mountain Research Station, Rapid City, SD 57702. E-mail: duresk@fs.fed.us

${ }^{2}$ South Dakota Department of Game, Fish and Parks, Rapid City, SD 57702. 
as rain in May and June. Temperatures during the growing season, April-September, range from $6.6^{\circ} \mathrm{C}$ to $22.2^{\circ} \mathrm{C}$ (Orr 1959). An annual growing season ranges from 97 to 154 days depending on elevation which ranges from $1067 \mathrm{~m}$ in the foothills to $2195 \mathrm{~m}$.

We sampled at sites from the foothills to the higher elevations. Plant species composition and diversity have been described by Thilenius (1972), Hoffman and Alexander (1987), and Uresk and Severson (1998). Estimated peak standing crop of vegetation in meadows ranges from 1170 to $2930 \mathrm{~kg} \cdot \mathrm{ha}^{-1}$ (Thomas et al. 1964, Pase and Thilenius 1968). Common plant species include Kentucky bluegrass (Poa pratensis), sedges (Carex spp.), western wheatgrass (Agropyron smithii), prairie dropseed (Sporobolus heterolepis), fleabane (Erigeron spp.), and yarrow (Achillea spp.).

\section{Methods}

Visual obstruction readings (VOR) and clipped herbage were sampled from mid-July to late August 2004. We used a Robel pole (Robel et al. 1970, Benkobi et al. 2000) with $1.27-\mathrm{cm}$ (0.5-inch) alternating white and gray bands. The bands were numbered beginning with 0 at the bottom. A spike $7.6 \mathrm{~cm}$ (3 inches) in length was attached to the bottom of the pole and was pushed into the ground to the bottom ring (Fig. 1). Visual obstruction readings were made from a distance of $4 \mathrm{~m}$ with the reader's eyes at a height of $1 \mathrm{~m}$. The number of the lowest visible band was recorded (Robel et al. 1970). For example, the 1st band was numbered as " 0 " and if it was visible, we recorded "0." At each pole station 4 VORs, 1 for each cardinal direction, were recorded and then averaged.

We used a stratified sampling design representing short, medium, and tall vegetation (based on visual inspection) to collect data (Benkobi et al. 2000). Ninety transects, 30 per stratum, were sampled from late July through early August with a mixture of grazed and ungrazed sites. Transects were located randomly within strata. Along each $200-\mathrm{m}$ transect, VOR was recorded at 20 stations spaced $10 \mathrm{~m}$ apart. Standing herbage was clipped within a $0.25-$ $\mathrm{m}^{2}$ circular hoop centered on the Robel pole at 4 stations along the transect $(50,100,150$, and $200 \mathrm{~m})$. All vegetation was clipped at ground level, oven dried at $60^{\circ} \mathrm{C}$ for 48 hours,

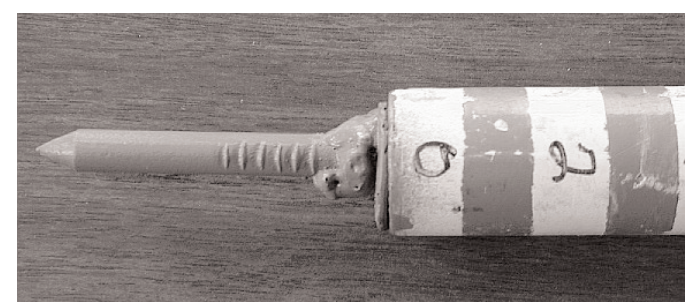

Fig. 1. Modified Robel pole with alternating white and gray, $1.27-\mathrm{cm}(0.5$-inch) bands on a $2.54-\mathrm{cm}$ (1-inch) diameter pole. A spike $7.6 \mathrm{~cm}$ ( $3 \mathrm{in}$.) long is attached to the bottom of the pole. The 1st band is numbered as 0 .

and weighed to the nearest $0.1 \mathrm{~g}$. Standing herbage was expressed as $\mathrm{kg} \cdot \mathrm{ha}^{-1}$.

All VORs and clipped herbage were averaged within transect for data analyses. Relationships between VOR and herbage were analyzed by piecewise regression and analyses of variance (Neter et al. 1989, SPSS 2003, SAS 2003). Probability plots were examined for normality of residuals. Significance was determined at $\alpha=0.05$.

Data collections on sites stratified by visual inspection were further analyzed for VOR categories by ISODATA cluster analysis (Ball and Hall 1967, del Morel 1975). Two variables, pole band and standing crop $\left(\mathrm{kg} \cdot \mathrm{ha}^{-1}\right)$, were evaluated for cluster analyses. Pole band was the key variable for the final cluster analyses. These new categories, classified by cluster analysis, ranged from tall to short vegetation. Sample size estimates were developed for the number of transects required to discriminate between and among the 3 visual obstruction categories. The number of stations and transects required to achieve estimates within $20 \%$ of the mean with an $80 \%$ confidence level were evaluated. The number of transects required to detect differences in standing herbage between bands at $\alpha=0.20$ were estimated based on nonoverlapping prediction intervals (Neter et al. 1989, Hettmansperger and McKean 1998).

\section{REsults}

Herbage ranged from 90 to $3820 \mathrm{~kg} \cdot \mathrm{ha}^{-1}$ with a mean of $1420 \mathrm{~kg} \cdot \mathrm{ha}^{-1}$. Visual obstruction bands had a mean of 6.4, and ranged from 0.2 to 20.4 for all transects. The relationship between standing herbage and visual obstruction was strongly linear within both the lower (0-5 bands) and upper ( $>5$ bands) regions of the piecewise regression model (Neter et al. 


\section{Black Hills Modified Robel Pole ( $P=0.8$ Prediction Limits)}

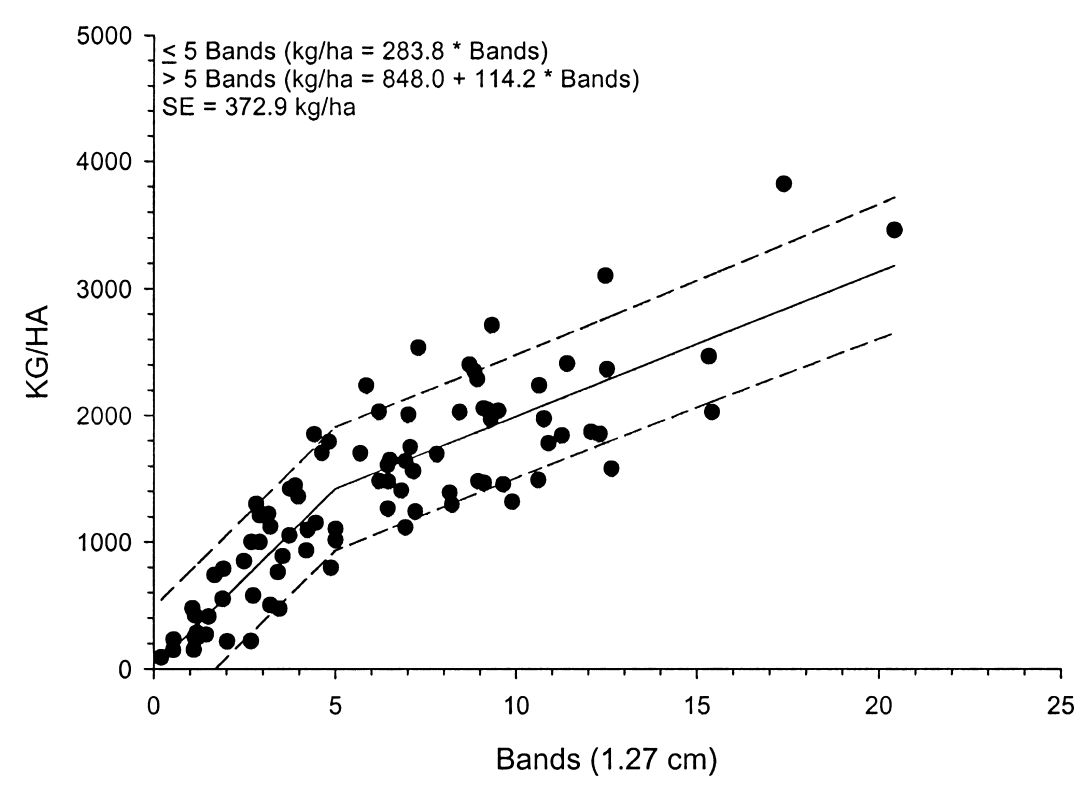

Fig. 2. Piecewise regression relationship between pole bands and standing herbage $\left(\mathrm{kg} \cdot \mathrm{ha}^{-1}\right)$ with $80 \%$ prediction bands for individual transects.

1989; Fig. 2). The regression model, intercepts, and coefficients were highly significant $(P \leq$ 0.001 ). Standard error of the estimate for a single transect mean was $372.9 \mathrm{~kg} \cdot \mathrm{ha}^{-1}$ (Fig. 2). Standing herbage can be predicted by applying the mean band reading per transect to 1 of 2 equations (Fig. 2): (1) $\leq 5$ bands: $\mathrm{kg} \cdot \mathrm{ha}^{-1}=$ $283.8 *$ Bands; and $(2)>5$ bands: $\mathrm{kg} \cdot \mathrm{ha}^{-1}=$ $848.0+114.2 *$ Bands.

Cluster analysis (ISODATA) based on pole bands was used to estimate the 3 visual obstruction categories. These VOR categories are short $(0.2-5.0$ bands), medium (5.1-10.3 bands), and tall (10.4-20.4 bands; Table 1). Assignment of standing herbage from VOR prediction estimates can be applied to categories in Table 1.

A minimum of 3 transects with 20 stations with 4 readings per station are required to detect differences between and among the VOR categories at $80 \%$ confidence to be within $20 \%$ of the mean (Benkobi et al. 2000). To detect differences between 2 bands (e.g., band 3 versus band 5), we estimate that 3 transects will provide sufficient precision at $\alpha=0.20$ based on nonoverlapping prediction intervals, which are based on the regression variance.

\section{Discussion}

The relationship between visual obstruction and standing herbage for meadow vegetation in the central Black Hills of South Dakota was highly significant $(P=0.001)$. Monitoring of key areas or allotments can be based on the mean VOR of transect(s) collected in the area and/or predicted standing herbage. The standard error of prediction was large for small visual obstruction readings (VOR), but the error remained constant throughout the range of prediction at $372.9 \mathrm{~kg} \cdot \mathrm{ha}^{-1}$. Transects located randomly within monitored areas will produce estimates that are sufficiently accurate and precise for management needs. Three transects are suggested for monitoring areas $\leq 259$ ha (1 section) for Black Hills vegetation.

Piecewise linear regression (Neter et. al. 1989 ) is useful when the regression of $Y$ (standing herbage) on $\mathrm{X}$ (bands) follows 1 linear relationship in 1 range of $\mathrm{X}$ (e.g., 0-5 bands) and a different linear relationship in another range of $\mathrm{X}$ (e.g., 5 bands). A combined model is produced for the full range of $\mathrm{X}$ with a break where the slope changes with the range of $X$. Piecewise models can meet at the break point 
TABLE 1. Categories of visual obstruction readings for short, medium, and tall by band number (1.27- $\mathrm{cm}$ band) on a modified Robel pole with corresponding $\mathrm{kg} \cdot \mathrm{ha}^{-1}$. Band represents visual obstruction reading (VOR). Categories are defined by cluster analyses (ISODATA) based on pole bands. The value for $\mathrm{kg} \cdot \mathrm{ha}^{-1}$ is based on a piecewise band-weight model.

\begin{tabular}{lccc}
\hline Categories & Minimum & $\bar{x}$ & Maximum \\
\hline SHORT $(n=41)^{\mathrm{a}}$ & & & \\
$\quad$ Band & 0.2 & 2.8 & 5.0 \\
$\mathrm{~kg} \cdot \mathrm{ha}^{-1}$ & 57 & 795 & 1419 \\
MEDIUM $(n=33)$ & & & \\
$\quad$ Band & 5.1 & 7.8 & 10.3 \\
$\mathrm{~kg} \cdot \mathrm{ha}^{-1}$ & 1430 & 1739 & 2024 \\
TALL $(n=16)$ & & & \\
$\quad$ Band & 10.4 & 12.9 & 20.4 \\
$\mathrm{~kg} \cdot \mathrm{ha}^{-1}$ & 2036 & 2321 & $3178+$ \\
\hline${ }^{\mathrm{N}}$ Number of transects & & &
\end{tabular}

or be separated, which is the same as estimating individual models in the 2 ranges of $X$. Estimating a combined model in which the pieces met at the break point provide the best description of the relationship between standing herbage and visual obstruction

The modified Robel pole is an excellent tool for monitoring the weight of vegetation throughout the plant growing season, even with herbivore grazing. Management decisions by area or pasture can also be accomplished by establishing limits of standing herbage with band numbers only. For example, with a target of $40 \%$ utilization based on the mean production of the tall category (ungrazed with an average of $2320 \mathrm{~kg} \cdot \mathrm{ha}^{-1}$ ), the pasture may be grazed to a level of approximately 5.0 bands (2.5 inches). At $60 \%$ use, the level would be approximately 3 bands ( 1.5 inches). Most management of livestock on our rangelands involves utilization of herbage; however, percent use is a difficult measurement to obtain with a high degree of accuracy and precision. Often it is obtained with subjective ocular estimates, without correction factors. Clipping herbage inside and outside of cages is expensive and time consuming (NAS-NRC 1962, Holechek et al.1989, Heady and Child 1994). The method requires many cages to obtain percent use with an acceptable degree of accuracy. Stocking rates of livestock could be varied for the pasture to achieve the desired herbage level based on Robel pole bands. Once the selected band had been achieved, then livestock would be removed to maintain the resource values and objective. The same resource objectives can be achieved by establishing limits on $\mathrm{kg}$. ha $^{-1}$ (Bement 1969).

The relationship of visual obstruction and standing herbage weight was developed for monitoring meadows in the Black Hills by VOR throughout the growing season. The method is accurate, precise, inexpensive, and easily learned. The Black Hills meadow study showed a segmented relationship (VOR versus standing herbage) and is not linear throughout the range of sampling as reported in other studies (Benkobi et al. 2000, Ganguli et al. 2000,Vermeire and Gillen 2001). Piecewise regression is similar to curvilinear regression but is simple for managers to apply.

Categories based on VOR and standing herbage define the range from short to tall (Table 1). Transects in short vegetation are generally heavily grazed, those in medium vegetation are moderately grazed; and those in tall vegetation are lightly grazed or ungrazed. Estimated herbage use at 3 bands is $63 \%$ and is considered heavy grazing. Five bands is approximately equivalent to $40 \%$ use (based on tall category) and is generally considered the standard at which livestock should be removed to maintain a healthy rangeland (Holechek et al. 1989, Heady and Child 1994). In key wildlife areas, leaving greater herbage reserves for food, nesting, and cover for nongame animals may be prudent. In the Black Hills, for example, white-tailed deer (Odocoileus virginianus dakotensis) fawns selected bed sites that averaged 14.8 bands on the Robel pole (Uresk et al. 1999). Fifty percent of fawns selected a band height $>14.8$.

A mosaic of these categories would provide both plant and animal diversity. Approximately $10 \%-15 \%$ in each of the short and tall visual obstruction categories is recommended for resource management, thus making available a full range of herbage for large herbivores and other wildlife (Mueller-Dombois and Ellenberg 1974). These areas should be rotated over time throughout the central hills.

\section{ACKNOWLEDGMENTS}

We thank John Kanta and Martin Tarby for assistance in collecting data. Partial funding was provided by Safari Club International, Greater Dacotah Chapter. Special thanks go to Rudy King, Rocky Mountain Research Station statistician, for providing statistical advice. 


\section{Literature Cited}

BaLl, G.H., AND D.J. HALL. 1967. A clustering technique for summarizing multivariate data. Behavioral Science 12:153-155.

Bement, R.E. 1969. A stocking-rate guide for beef production on blue-grama range. Journal of Range Management 22:83-86.

Benkobi, L., D.W. Uresk, G. Schenbeck, And R.M. King. 2000. Protocol for monitoring standing crop in grasslands using visual obstruction. Journal of Range Management 53:627-633.

DEL Morel, R. 1975. Vegetation clustering by means of ISODATA: revision by multiple discriminant analysis. Vegetatio 29:179-190.

Ganguli, A.C., L.T. Vermeire, R.B. Mitchell, and M.C. WALLACE. 2000. Comparison of four nondestructive techniques for estimating standing crop in shortgrass plains. Agronomy Journal 92:1211-1215.

Heady, H.F., AND R.D. Child 1994. Rangeland ecology and management. Westview Press, Boulder, CO. 519 pp.

Hettmansperger, T.P., and J.W. McKean. 1998. Robust nonparametric statistical methods. John Wiley \& Sons, New York. 467 pp.

Hoffman, G.R., AND R.R. Alexander. 1987. Forest vegetation of the Black Hills National Forest of South Dakota and Wyoming: a habitat type classification. Research Paper RM-276. Fort Collins, CO: USDA Forest Service, Rocky Mountain Forest and Range Experiment Station. 48 pp.

Holechek, J.L., R.D. Pieper, and C.H. Herbel. 1989. Range management: principles and practices. Prentice Hall, Upper Saddle River, NJ. 501 pp.

Mueller-Dombois, D., And H. Ellenberg. 1974. Aims and methods of vegetation ecology. John Wiley \& Sons, New York. 547 pp.

NAS-NRC. 1962. Basic problems and techniques in range research. National Academy of Sciences-National Research Council, Publication No. 890, Washington, DC. $341 \mathrm{pp}$.

Neter, J., W. Wasserman, and W.H. Kutner. 1989. Applied linear regression models. 2nd edition. Irwin, Homewood, IL. 667 pp.

ORR, H.K. 1959. Precipitation and stream flow in the Black Hills. Station Paper Rm-44, Fort Collins, CO: U.S. Department of Agriculture, Rocky Mountain Forest and Range Experiment Station. 25 pp.

Pase, C.P., AND J.F. Thilenius. 1968. Composition, production, and site factors of some grasslands in the Black Hills of South Dakota. USDA Forest Service
Research Note RM-103, Rocky Mountain Forest and Range Experiment Station, Fort Collins, CO. 8 pp.

Pechanec, J.F., And G.D. Pickford. 1937. A weight estimate method for determination of range or pasture production. Journal of the American Society of Agronomy 29:894-904.

Robel, R.J., J.N. Briggs, A.D. Dayton, and L.C. Hulbert. 1970. Relationships between visual obstruction measurements and weight of grassland vegetation. Journal of Range Management 23:295-297.

SAS. 2003. SAS Institute, Inc., Cary, NC.

SEverson, K.E., AND C.E. BOLDT. 1977. Options for Black Hills Forest owners: timber, forage, or both. Rangeman's Journal 4:13-15.

SPSS. 2003. SPSS Base 12.0 for Windows User's Guide. SPSS, Inc. $703 \mathrm{pp}$.

Thilenius, J.F. 1972. Classification of deer habitat in the ponderosa pine forest of the Black Hills, South Dakota. Research Paper RM-91, USDA Forest Service, Rocky Mountain Forest and Range Experiment Station, Fort Collins, CO. 28 pp.

Thomas, J.R., H.R. Cosper, AND W. Bever. 1964. Effects of fertilizers on the growth of grass and its use by deer in the Black Hills of South Dakota. Agronomy Journal 56:223-226.

Uresk, D.W., T.A. Benzon, K.E. Severson, and L. BenKовI. 1999. Characteristics of white-tailed deer fawn beds, Black Hills, South Dakota. Great Basin Naturalist 59:348-354.

Uresk, D.W., C.B. Edminister, and K.E. Severson. 2000. Wood and understory production under a range of pondersoa pine stocking levels, Black Hills, South Dakota. Western North American Naturalist 60:93-97.

Uresk, D.W., And K.E. Severson. 1998. Response of understory species to changes in ponderosa pine stocking levels in the Black Hills. Great Basin Naturalist 58:312-327.

Vermeire, L.T., A.C. Gangull, and R.L. Gillen. 2002. A robust model for estimating standing crop across vegetation types. Journal of Range Management 55: 494-497.

Vermeire, L.T., AND R.L. GILLEN. 2001. Estimating herbage standing crop with visual obstruction in tall grass prairie. Journal of Range Management 54:57-60.

Volesky, J.D., W.H. SCHACHT, AND P.E. REece. 1999. Leaf area, visual obstruction, and standing crop relationships on Sandhills rangeland. Journal of Range Management 52:494-499.

Received 7 July 2005 Accepted 28 July 2006 